\title{
RESEARCH
}

Open Access

\section{Equity of primary care service delivery for low income "sicker" adults across 10 OECD countries}

\author{
Simone Dahrouge ${ }^{1 *}$ D, William Hogg ${ }^{2}$, Elizabeth Muggah ${ }^{3}$ and Ted Schrecker ${ }^{4}$
}

\begin{abstract}
Background: Despite significant investments to support primary care internationally, income-based inequities in access to quality health care are present in many high-income countries. This study aims to determine whether low- and middle-income groups are more likely to report poor quality of primary care (PC) than high-income groups cross-nationally.
\end{abstract}

Methods: The 2011 Commonwealth Fund Telephone Survey of Sicker Adults is a cross-sectional study across eleven countries. Respondents were recruited from randomly selected households. We used data from surveys conducted in Australia, Canada, France, Germany, the Netherlands, New Zealand, Norway, Sweden, the United Kingdom, and the United States. We identified all questions relating to primary care performance, and categorized these into five dimensions: 1) access to care, 2) coordination 3) patient-centered care, and 4) technical quality of care. We used logistic regression with low and middle-income as the comparison groups and high-income as the referent.

Results: Fourteen thousand two hundred sixty-two respondents provided income data. Countries varied considerably in their extent of income disparity. Overall, 24.7\% were categorized as low- and 13.9\% as high-income. The odds of reporting poor access to care were higher for low- and middle-income than high-income respondents in Canada, New Zealand and the US. Similar results were found for Sweden and Norway on coordination; the opposite trend favoring the low- and middle-income groups was found in New Zealand, United Kingdom, and the United States. The odds of reporting poor patient-centered care were higher for low-income than high-income respondents in the Netherlands, Norway, and the US; in Australia, this was true for low- and middle-income respondents. On technical quality of care, the odds of reporting poor care were higher for the low- and middle-income comparisons in Canada and Norway; in Germany, the odds were higher for low-income respondents only. The odds of reporting poor technical quality of care were higher for high-income than low-income respondents in the Netherlands.

Conclusion: Inequities in quality PC for low and middle income groups exist on at least one dimension in all countries, including some that in theory provide universal access. More research is needed to fully understand equity in the PC sector.

Keywords: Primary care, Household income, Health equity

\footnotetext{
* Correspondence: sdahrouge@bruyere.org

${ }^{1}$ Department of Family Medicine and Scientist at the Bruyère Research

Institute and the Institute of Clinical Evaluative Sciences, University of Ottawa,

Ottawa, Canada

Full list of author information is available at the end of the article
}

(c) The Author(s). 2018 Open Access This article is distributed under the terms of the Creative Commons Attribution 4.0 International License (http://creativecommons.org/licenses/by/4.0/), which permits unrestricted use, distribution, and reproduction in any medium, provided you give appropriate credit to the original author(s) and the source, provide a link to the Creative Commons license, and indicate if changes were made. The Creative Commons Public Domain Dedication waiver (http://creativecommons.org/publicdomain/zero/1.0/) applies to the data made available in this article, unless otherwise stated. 


\section{Introduction}

Equity is a valued aspect of most health care delivery systems. The International Society for Equity in Health (ISEqH) has defined equity as "the absence of potentially remediable, systematic differences in one or more aspects of health across socially, economically, demographically, or geographically defined population groups or subgroups" [1]. Evidence of health disparities related to income inequality has been shown consistently in many parts of the world [2-4]. More specifically, income-based inequities in access to quality health care have been demonstrated in many high-income countries, including some that in theory provide universal access to publicly funded care [5]. Primary care (PC) is the bedrock of a health care system. PC providers, usually a family physician or nurse practitioner, offer patient-centered care spanning the individual's life trajectory and health needs [6]. They coordinate and facilitate access to health services across sectors. Deficiencies in that foundation can have serious repercussions. A health system's orientation toward PC is related to better experience of care [7] and better health outcomes [4, 8]. Additionally, Starfield and colleagues demonstrated that health care systems oriented to PC are also associated with greater health equity $[7,9,10]$.

The World Health Organization has advocated for strong PC sectors within health care systems, [11] and significant investments have been made to support PC internationally [12]. While past work has demonstrated the value of a greater health system orientation to PC, including enhanced system efficiency, better population health, and more equitable access to health services $[8$, 13], inequities within the PC sector itself remain largely unexamined. When access to PC is defined as the frequency of contact with the PC provider, several studies conducted in a setting where the costs of physician visits are covered by a universal insurer, found pro-poor or neutral effect of low socio-economic measures on access [14], while those conducted in a privatized settings found the opposite [15]. Studies assessing the equitable receipt of services within that sector are mixed. Studies showing equivalent or better care for vulnerable populations [16-18] relied predominantly on processes of care indicators carried out by the PC provider, while those revealing meaningful gaps, relied on measures of whether the individuals had undergone recommended tests, $[19,20]$ indicators that require an action by the individual.

Given the PC sector's role in reducing gaps in the health of the population across sociodemographic strata, it may be informative to examine more broadly whether access to that sector across several dimensions, and within the same geo-political context to determine the fairness of that sector itself [21]. The Commonwealth Fund is a private non-profit organization based in the
United States that routinely surveys patients and health care providers in OECD countries in order to measure health care performance across multiple developed nations. In 2011 they surveyed a large sample of "sicker" adults across eleven countries and captured detailed information on their experiences with the health care system [7]. Using patient survey data collected in 2011 across ten of these 11 Organization for Economic Cooperation and Development (OECD) countries by the Commonwealth Fund (Switzerland was omitted for reasons explained below), we conducted a cross-country comparison of the experience of low-income individuals across four dimensions of PC: 1) access to care, 2) coordination 3) patient-centered care, and 4) technical quality of care.

The goal of this study is to examine 1) the relationship between income level and the experience of quality primary health care across the four central dimensions of care in each country, and 2) whether equity of PC service varies across countries.

\section{Methods \\ Sample}

This study relied on respondents participating in the 2011 Commonwealth Fund Telephone Survey of Sicker Adults. Respondents were eligible if they 1 ) were in poor to fair health, 2) had received medical care for a chronic or serious illness, a major injury, or a disability in the previous year, 3) had been hospitalized in the past 2 years for reasons other than a complication-free childbirth, or 4) had undergone major surgery in the past 2 years.

\section{Survey design}

The 2011 Commonwealth Fund Telephone Survey of Sicker Adults is a cross-sectional study across eleven countries: Australia, Canada, France, Germany, the Netherlands, New Zealand, Norway, Sweden, Switzerland, the United Kingdom, and the United States. Briefly, between March and June 2011, randomly selected households were contacted, and the resident who a) was over 18 years of age and b) had the most recent birthday was asked to respond to the questionnaire. Interviewers asked respondents a series of questions and noted their answers on a Likert scale. Details of the survey methodology are provided in Schoen et al. [7]. Country level response rates ranged from 16 to $42 \%$. The minimum sample size required to detect an effect in each country was 750 respondents. However, several countries contributed additional funds to increase their sample size and allow additional power. The total number of participants ranged from 750 in New Zealand to 4804 in Sweden. A weight reflecting the population distribution of age, sex, level of education, and region was established in order to allow population-based estimates. 


\section{Respondent profile}

The survey captured respondent household income, demographics (age, sex, immigration status, level of education), and health (self-reported measures of various chronic conditions) measures. Household income was captured in the survey using a six-option categorical variable for all countries except Switzerland and the United States. The options reflected values relative to that country's respective median household income as follows: less than $50 \%$ of median, between 50 and $89 \%$ of median, between 90 and 109\% median, between 110 and 149\% median, between 150 and 200\% median, and more than $200 \%$ median. In the United States, a five-item scale that reflected the country's defined Federal Poverty Level was used [7]. Switzerland opted out of the income related question; as such, that country was excluded in this study. Each respondent was also asked to report the number of adults and children in their household (Additional file 1).

\section{Patient experience with PC}

We identified all questions relating to PC performance, and mapped these according to previously defined dimension of care [22]. We identified five dimensions covered by the question surveys: 1) access to care, 2) continuity of care, 3) patient-centered care, 4) coordination, and 5) technical quality of care. However, because there was only a single question related to continuity of care, and a single question would not provide adequate coverage of that dimension, we dropped this dimension from our analyses. All other dimensions consisted of 3 to 6 questions. Likert scale questions were dichotomized into: acceptable and less than acceptable. For instance, in the original survey, the question "How often does your regular doctor or someone in your doctor's practice help coordinate or arrange the care you receive from other doctors and places, such as make appointments?" could be answered 1) always, 2) often, 3) sometimes, or 4) rarely/never (Additional file 1). We classified the first two as acceptable, and the latter two as less than acceptable. If a respondent's answer to at least one question within a dimension was ranked as less than acceptable, that respondent was coded as having received "poor" care on that dimension. Although this approach may be seen as introducing a negative bias in the results, it can also be interpreted as maximizing sensitivity to departures from the norm of equity [23].

\section{Analysis}

Individuals who reported having a household income in the lowest income level were categorized as low-income; those with household income in the two highest income levels were categorized as high-income. All others were assigned to the middle-income category.
We calculated the proportion of respondents who reported "poor" care for each income group. We used logistic regression to compare the responses of low- and middle-income respondents to those in the high-income category. Each of the four performance dimensions were, in turn, the dependent variables, while household income acted as the main independent variable, with the high-income level as a reference. The main analysis was unweighted and adjusted only for the number of individuals in the household to reflect available resources per person [24]. These analyses were repeated using population weight to produce an estimate reflecting the country's population.

\section{Results}

Of the 17,167 respondents, 14,262 (83.1\%) provided income data (Table 1). Countries varied considerably in their extent of income disparity. Overall, $24.7 \%$ were categorized as low- (range: 13.2, 34.3\%) and $13.9 \%$ as high- (range: 2.4, 21.4\%) income. The United States had the largest spread in income, with $50.4 \%$ of individuals falling in either extreme income groups (low or high), while the United Kingdom had the narrowest spread (15.6\%). There was an evident gradient relationship between income and several respondent characteristics (Table 2). Individuals with lower income had fewer people in the households, were older, had lower education, and reported worse health. They were also much more likely to be female. Individuals having not provided income information had a profile that resembled more closely that of individuals with low or medium income.

Questions relating to the performance of the PC system had a high completion rate: $99,94,96$, and $99 \%$ of eligible respondents for access, coordination, patient-centered care, and technical quality of care, respectively. Table 2 shows the proportion of eligible individuals in each income category whose responses indicated "poor" care. Consistently, individuals in the low income category had higher prevalence of "poor" care than those in the higher income group, while those in the middle income category usually had an intermediate score. The spread was highest for technical quality of care; with scores of 53.1, 50.1 and $45.5 \%$ reporting "poor" care in the low, middle, and high income group, respectively. Amongst the individuals who did not report their household income, "poor" care was less likely to have been reported than in any other income group for Access: 53.0\%; Coordination 56.8; Patient Centered Care: 43.9. Nearly half of these individuals (49.8\%) had "poor" Technical quality of care: $49.8 \%$. Table 3 reports the odds ratio of low- and middle-income individuals reporting "poor" care relative to high-income individuals, after adjusting for the number of people living in the 
Table 1 Description of respondents by income group (Low, Medium, High)

\begin{tabular}{|c|c|c|c|c|c|c|c|c|c|c|c|}
\hline Countries & Overall & Aus & Can & $\mathrm{Fr}$ & Ger & NT & NZ & NW & SW & UK & US \\
\hline N & 17,167 & 1,500 & 3,958 & 1,001 & 1,200 & 1,000 & 750 & 753 & 4,804 & 1,001 & 1,200 \\
\hline $\begin{array}{l}\text { With income data } \\
(\%)\end{array}$ & 83.1 & 82.8 & 80.9 & 87.4 & 71.5 & 74.4 & 85.3 & 90.7 & 87.7 & 83.1 & 81.0 \\
\hline \multicolumn{12}{|c|}{ \# in the household (Mean, SD) } \\
\hline Low & $1.7(1.1)$ & $1.8(1.0)$ & $1.8(1.1)$ & $1.9(1.3)$ & $1.7(1.0)$ & $1.8(1.2)$ & $1.9(1.3)$ & $1.6(0.8)$ & $1.4(0.8)$ & $1.9(1.5)$ & $1.0(1.5)$ \\
\hline Medium & $2.5(1.3)$ & $2.6(1.4)$ & $2.6(1.4)$ & $2.7(1.4)$ & $2.5(1.3)$ & $2.4(1.4)$ & $2.7(1.5)$ & $2.1(1.0)$ & $2.2(1.2)$ & $2.9(1.2)$ & $2.4(1.4)$ \\
\hline High & $3.0(1.4)$ & $3.2(1.1)$ & $3.2(1.4)$ & $3.3(1.4)$ & $2.7(1.3)$ & $3.3(1.6)$ & $3.3(1.4)$ & $3.2(1.4)$ & $2.9(1.3)$ & $3.2(1.2)$ & $2.8(1.9)$ \\
\hline Unknown & $2.2(1.3)$ & $2.2(1.3)$ & $2.3(1.4)$ & $2.1(1.1)$ & $2.4(1.3)$ & $2.4(1.6)$ & $2.4(1.3)$ & $1.9(1.0)$ & $1.9(1.1)$ & $2.6(1.3)$ & $2.1(1.4)$ \\
\hline
\end{tabular}

Age (years) (mean years, SD)

$\begin{array}{lllllllllllll}\text { Low } & 63.4(16.7) & 65.7(13.4) & 61.8(16.3) & 57.1(18) & 60.3(18.1) & 62.7(18) & 63.9(15.1) & 65(13.3) & 67(16.9) & 61.6(16.7) & 63.4(16.8) \\ \text { Medium } & 55.4(16.1) & 54.3(14.6) & 53.2(16.0) & 51.7(15.5) & 52.9(15.3) & 58.1(17.3) & 53.2(15.8) & 60(13.6) & 57.8(16.3) & 49.6(15.2) & 61.0(16.2) \\ \text { High } & 50.5(13.0) & 48.6(11.8) & 48.3(12.1) & 51.7(13.9) & 49.4(13.1) & 51.3(14.5) & 49.9(10.7) & 51(12.9) & 51.5(13.4) & 51.7(12.3) & 54.5(14.8) \\ \text { Unknown } & 61.0(18) & 62.9(16.7) & 60.0(17.3) & 60.7(19) & 56.0(18.0) & 62.9(18.7) & 61.6(15.5) & 64.5(18.0) & 62.3(18.4) & 55.0(19.4) & 67.1(16.6)\end{array}$

Female (\%)

$\begin{array}{llllllllllll}\text { Low } & 68.1 & 70.9 & 69.3 & 71.3 & 64.6 & 67.3 & 71.5 & 70.0 & 65.8 & 50.0 & 71.3 \\ \text { Medium } & 55.4 & 58.7 & 62.0 & 61.8 & 63.1 & 51.4 & 65.0 & 45.4 & 47.7 & 51.0 & 66.2 \\ \text { High } & 50.1 & 56.5 & 64.2 & 44.7 & 48.7 & 48.0 & 56.8 & 53.2 & 34.6 & 55.0 & 55.8 \\ \text { Unknown } & 69.4 & 74.4 & 66.9 & 70.6 & 71.3 & 83.2 & 70.0 & 71.4 & 62.2 & 66.3 & 72.4\end{array}$

College/University (\%)

\begin{tabular}{|c|c|c|c|c|c|c|c|c|c|c|c|}
\hline Low & 17.5 & 14.1 & 21.0 & 9.3 & 43.3 & 9.4 & 39.6 & 2.8 & 13.9 & 5.5 & 19.5 \\
\hline Medium & 35.1 & 32.7 & 47.4 & 30.5 & 55.3 & 26.0 & 54.8 & 17.9 & 29.5 & 17.5 & 40.1 \\
\hline High & 61.8 & 58.8 & 69.7 & 65.8 & 63.4 & 68.0 & 73.2 & 36.5 & 55.0 & 75.0 & 73.1 \\
\hline Unknown & 28.4 & 24.3 & 39.3 & 14.6 & 31.6 & 15.0 & 51.5 & 8.7 & 23.1 & 23.0 & 31.0 \\
\hline
\end{tabular}

Immigrant (\%)

$\begin{array}{llllllllllll}\text { Low } & 13.1 & 19.5 & 15.9 & 7.3 & 13.8 & 11.7 & 19.0 & 0.9 & 10.9 & 14.5 & 9.9 \\ \text { Medium } & 12.4 & 17.5 & 16.7 & 9.5 & 14.4 & 8.1 & 23.5 & 3.8 & 9.2 & 14.4 & 8.9 \\ \text { High } & 11.0 & 19.9 & 14.6 & 7.9 & 8.9 & 6.0 & 19.2 & 4.0 & 6.6 & 15.0 & 9.1 \\ \text { Unknown } & 14.8 & 21.7 & 20.7 & 8.8 & 16.5 & 8.6 & 21.8 & 4.3 & 10.4 & 15.4 & 5.4\end{array}$

Self-reported health > Good (\%)

\begin{tabular}{|c|c|c|c|c|c|c|c|c|c|c|c|}
\hline Low & 48.0 & 52.9 & 46.3 & 41.3 & 32.6 & 35.2 & 65.8 & 32.7 & 61.2 & 37.3 & 35.8 \\
\hline Medium & 68.0 & 71.7 & 68.4 & 58.7 & 54.0 & 44.6 & 79.3 & 55.2 & 77.3 & 67.7 & 60.5 \\
\hline High & 82.1 & 82.4 & 79.7 & 65.8 & 66.4 & 64.0 & 88.7 & 80.2 & 88.0 & 80.0 & 81.7 \\
\hline Unknown & 59.1 & 62.6 & 61.1 & 39.7 & 52.6 & 40.2 & 67.3 & 43.5 & 71.6 & 61.5 & 56.4 \\
\hline
\end{tabular}

\# of Chronic Conditions ${ }^{\mathrm{a}}$ (mean)

\begin{tabular}{llllllllllll} 
Low & $2.2(1.5)$ & $2.5(1.4)$ & $2.3(1.6)$ & $1.9(1.5)$ & $2.4(1.6)$ & $1.8(1.4)$ & $2.1(1.4)$ & $2.2(1.5)$ & $1.7(1.3)$ & $2.3(1.7)$ & $2.9(1.7)$ \\
Medium & $1.4(1.3)$ & $1.7(1.5)$ & $1.5(1.4)$ & $1.4(1.3)$ & $1.6(1.4)$ & $1.4(1.3)$ & $1.3(1.2)$ & $1.6(1.3)$ & $1.2(1.2)$ & $1.3(1.4)$ & $2.2(1.6)$ \\
High & $11(1.2)$ & $1.1(1.2)$ & $1.2(1.3)$ & $1(1.1)$ & $1.2(1.1)$ & $1.1(1.1)$ & $0.9(1)$ & $1(0.9)$ & $0.8(1)$ & $1.2(1.5)$ & $1.5(1.3)$ \\
Unknown & $1.6(1.4)$ & $1.9(1.5)$ & $1.6(1.4)$ & $1.7(1.4)$ & $1.7(1.4)$ & $1.6(1.3)$ & $1.7(1.4)$ & $1.6(1.4)$ & $1.1(1.2)$ & $1.6(1.6)$ & $2.2(1.6)$ \\
\hline
\end{tabular}

Aus = Australia, Can = Canada, Fr = France, Ger = Germany, NT = Netherlands, NZ = New Zealand, NW = Norway, SW = Sweden, UK = United States ${ }^{a}$ The chronic conditions assessed were: Hypertension, Heart disease, Diabetes, Joint pain/Arthritis, Asthma/COPD/any other chronic lung problem, Depression/ Anxiety/other mental health problem, Cancer, Chronic back pain

household. The results for each country are depicted in Fig. 1. Weighing the records according to their socio-demographic profile to allow population-based estimates, had no impact on the results to two decimal places.
With one exception (Norway), individuals with low and middle income were more likely to report having had poor access, compared to those with high income. This reached statistical significance for Canada, the United States, and New Zealand. An apparent dose-response 
Table 2 Percentage of individuals in each income group reporting poor quality of care relative to all eligible respondents in that category

\begin{tabular}{|c|c|c|c|c|c|c|c|c|c|c|c|c|c|c|c|c|}
\hline \multirow{2}{*}{$\begin{array}{l}\text { Indicators } \\
\text { Income }\end{array}$} & \multicolumn{4}{|l|}{ Access } & \multicolumn{4}{|c|}{ Coordination } & \multicolumn{4}{|c|}{ Patient Centered Care } & \multicolumn{4}{|c|}{ Technical Quality of Care } \\
\hline & $\mathrm{n}$ & Low & Middle & High & $\mathrm{n}$ & Low & Middle & High & $\mathrm{N}$ & Low & Middle & High & $N$ & Low & Middle & High \\
\hline Overall & 14,143 & 64.1 & 63.5 & 60.2 & 13,419 & 63.5 & 57.5 & 60.6 & 13,718 & 49.5 & 46.4 & 45.1 & 11,008 & 53.1 & 50.1 & 45.5 \\
\hline Sweden & 4,149 & 63.2 & 64.6 & 61.7 & 3679 & 70.9 & 62.0 & 61.3 & 3,961 & 62.0 & 59.0 & 60.0 & 3,229 & 66.7 & 64.5 & 61.4 \\
\hline Canada & 3,191 & 79.1 & 78.4 & 74.4 & 3,073 & 55.7 & 51.0 & 49.1 & 3,061 & 48.9 & 43.7 & 47.2 & 2,517 & 44.7 & 40.6 & 28.1 \\
\hline Australia & 1,236 & 63.6 & 68.5 & 63.2 & 1,214 & 59.8 & 62.8 & 69.1 & 1,215 & 37.0 & 34.6 & 27.0 & 950 & 48.4 & 45.2 & 40.9 \\
\hline United States & 964 & 76.8 & 70.6 & 52.2 & 943 & 60.1 & 44.7 & 55.6 & 915 & 43.9 & 38.6 & 31.4 & 826 & 43.3 & 40.6 & 35.4 \\
\hline France & 871 & 42.7 & 52.3 & 43.3 & 862 & 79.9 & 83.1 & 85.7 & 866 & 49.2 & 49.9 & 41.4 & 643 & 65.3 & 69.3 & 57.1 \\
\hline Germany & 851 & 57.1 & 56.9 & 50.4 & 849 & 78.6 & 76.6 & 80.5 & 827 & 38.2 & 40.6 & 34.2 & 608 & 51.4 & 37.8 & 32.0 \\
\hline United Kingdom & 832 & 44.7 & 38.7 & 33.3 & 808 & 45.0 & 29.9 & 58.3 & 825 & 42.7 & 21.9 & 16.0 & 631 & 35.2 & 19.3 & 41.2 \\
\hline Netherlands & 741 & 55.1 & 52.4 & 45.9 & 718 & 70.7 & 66.4 & 78.1 & 734 & 45.2 & 38.6 & 31.1 & 596 & 52.2 & 52.6 & 70.6 \\
\hline Norway & 671 & 54.5 & 53.1 & 59.6 & 656 & 66.4 & 54.7 & 55.6 & 678 & 81.2 & 66.3 & 62.5 & 554 & 68.8 & 67.7 & 52.5 \\
\hline New Zealand & 637 & 50.0 & 53.6 & 41.3 & 617 & 39.9 & 46.5 & 56.3 & 636 & 27.2 & 35.9 & 28.2 & 454 & 39.6 & 38.4 & 32.7 \\
\hline
\end{tabular}

Individuals with incomplete data in the domain studied were excluded (Access $=119$, Coordination $=843$, Patient Centered Care $=544$, Technical Quality of Care 133). These were distributed across all countries. 11,141 were eligible to respond to the technical quality of care questions

relationship was observed where the odds ratio for the lower-income comparison tended to be higher than that of the middle-income comparison.

There was no consistent relationship between income status and the quality of care coordination. Individuals in the lower income group living in Sweden and Norway were more likely to report lower coordination, while in the United Kingdom, New Zealand, and to some extent, the United States, it was individuals in the highest income bracket that reported lower care coordination.
With one exception (Canada), patients in the lower income groups were more likely to report deficiencies in patient centered care. This reached statistical significance in Australia, the United States, the United Kingdom, the Netherlands, and Norway.

Two countries, the United Kingdom and the Netherlands, showed meaningful and statistically significant better measures of technical quality of care for individuals in the lower income bracket. In Canada, Germany and Norway, the effect was in the opposite direction.

Table 3 Odds of reporting "poor" care for low and middle income categories relative to upper income category - adjusted for number of individuals in the household

\begin{tabular}{|c|c|c|c|c|c|c|c|c|}
\hline & \multicolumn{2}{|c|}{ Access } & \multicolumn{2}{|c|}{ Coordination } & \multicolumn{2}{|c|}{ Patient Centered Care } & \multicolumn{2}{|c|}{ Technical Quality of Care } \\
\hline & Low Income & Middle Income & Low Income & Middle Income & Low Income & Middle Income & Low Income & Middle Income \\
\hline Overall & $\begin{array}{c}1.34 \\
(1.19-1.51)\end{array}$ & $\begin{array}{c}1.22 \\
(1.10-1.35)\end{array}$ & $\begin{array}{c}1.09 \\
(0.97-1.24)\end{array}$ & $\begin{array}{c}0.87 \\
(0.80-0.96) \\
\end{array}$ & $\begin{array}{c}1.22 \\
(1.09-1.37)\end{array}$ & $\begin{array}{c}1.06 \\
(0.96-1.18)\end{array}$ & $\begin{array}{c}1.24 \\
(1.08-1.42)\end{array}$ & $\begin{array}{c}1.15 \\
(1.02-1.31)\end{array}$ \\
\hline Sweden & $\begin{array}{c}1.16 \\
(0.92,1.46)\end{array}$ & $\begin{array}{c}1.18 \\
(0.99,1.42)\end{array}$ & $\begin{array}{c}1.36^{*} \\
(1.06,1.75)\end{array}$ & $\begin{array}{c}0.97 \\
(0.80,1.18)\end{array}$ & $\begin{array}{c}1.25 \\
(0.99,1.58)\end{array}$ & $\begin{array}{c}1.03 \\
(0.86,1.24)\end{array}$ & $\begin{array}{c}1.22 \\
(0.93,1.60)\end{array}$ & $\begin{array}{c}1.13 \\
(0.90,1.42)\end{array}$ \\
\hline Canada & $\begin{array}{c}1.51 * \\
(1.13,2.01)\end{array}$ & $\begin{array}{c}1.31 * \\
(1.01,1.69)\end{array}$ & $\begin{array}{c}1.28 \\
(1.00,1.65) \\
\end{array}$ & $\begin{array}{c}1.07 \\
(0.85,1.33) \\
\end{array}$ & $\begin{array}{c}1.13 \\
(0.88,1.45)\end{array}$ & $\begin{array}{c}0.88 \\
(0.71,1.10) \\
\end{array}$ & $\begin{array}{c}1.99 * \\
(1.44,2.75) \\
\end{array}$ & $\begin{array}{c}1.72 * \\
(1.26,2.33) \\
\end{array}$ \\
\hline Australia & $\begin{array}{c}1.16 \\
(0.79,1.70)\end{array}$ & $\begin{array}{c}1.32 \\
(0.95,1.83)\end{array}$ & $\begin{array}{c}0.68 \\
(0.46,1.01)\end{array}$ & $\begin{array}{c}0.76 \\
(0.54,1.06)\end{array}$ & $\begin{array}{c}1.76^{*} \\
(1.18,2.62)\end{array}$ & $\begin{array}{c}1.47 * \\
(1.04,2.08)\end{array}$ & $\begin{array}{c}1.39 \\
(0.89,2.18)\end{array}$ & $\begin{array}{c}1.21 \\
(0.80,1.82)\end{array}$ \\
\hline United States & $\begin{array}{c}3.38 * \\
(2.31,4.93) \\
\end{array}$ & $\begin{array}{c}2.30^{*} \\
(1.66,3.19) \\
\end{array}$ & $\begin{array}{c}1.24 \\
(0.87,1.77) \\
\end{array}$ & $\begin{array}{c}0.65^{*} \\
(0.47,0.89) \\
\end{array}$ & $\begin{array}{c}1.75^{*} \\
(1.21,2.54) \\
\end{array}$ & $\begin{array}{c}1.37 \\
(0.98,1.92) \\
\end{array}$ & $\begin{array}{c}1.41 \\
(0.94,2.10)\end{array}$ & $\begin{array}{c}1.25 \\
(0.86,1.80)\end{array}$ \\
\hline France & $\begin{array}{c}1.08 \\
(0.51,2.31)\end{array}$ & $\begin{array}{c}1.50 \\
(0.71,3.13)\end{array}$ & $\begin{array}{c}0.61 \\
(0.21,1.81) \\
\end{array}$ & $\begin{array}{c}0.82 \\
(0.28,2.39)\end{array}$ & $\begin{array}{c}1.40 \\
(0.64,3.06)\end{array}$ & $\begin{array}{c}1.40 \\
(0.65,3.01)\end{array}$ & $\begin{array}{c}1.15 \\
(0.46,2.87)\end{array}$ & $\begin{array}{c}1.47 \\
(0.60,3.62)\end{array}$ \\
\hline Germany & $\begin{array}{c}1.37 \\
(0.85,2.23) \\
\end{array}$ & $\begin{array}{c}1.31 \\
(0.88,1.96)\end{array}$ & $\begin{array}{c}0.96 \\
(0.53,1.74) \\
\end{array}$ & $\begin{array}{c}0.81 \\
(0.49,1.33) \\
\end{array}$ & $\begin{array}{c}1.35 \\
(0.81,2.25)\end{array}$ & $\begin{array}{c}1.34 \\
(0.88,2.06)\end{array}$ & $\begin{array}{c}2.32 * \\
(1.27,4.23)\end{array}$ & $\begin{array}{c}1.30 \\
(0.76,2.22)\end{array}$ \\
\hline United Kingdom & $\begin{array}{c}1.34 \\
(0.56,3.24)\end{array}$ & $\begin{array}{c}1.12 \\
(0.50,2.51)\end{array}$ & $\begin{array}{c}0.49 \\
(0.20,1.22) \\
\end{array}$ & $\begin{array}{c}0.30 * \\
(0.13,0.68) \\
\end{array}$ & $\begin{array}{c}4.26^{*} \\
(1.34,13.51)\end{array}$ & $\begin{array}{c}1.54 \\
(0.51,4.65) \\
\end{array}$ & $\begin{array}{c}0.59 \\
(0.20,1.76)\end{array}$ & $\begin{array}{c}0.31 * \\
(0.11,0.88)\end{array}$ \\
\hline Netherlands & $\begin{array}{c}1.71 \\
(0.99,2.95)\end{array}$ & $\begin{array}{c}1.45 \\
(0.87,2.40)\end{array}$ & $\begin{array}{c}0.86 \\
(0.45,1.66)\end{array}$ & $\begin{array}{c}0.64 \\
(0.35,1.17)\end{array}$ & $\begin{array}{c}1.90^{*} \\
(1.07,3.38) \\
\end{array}$ & $\begin{array}{c}1.44 \\
(0.84,2.47)\end{array}$ & $\begin{array}{c}0.44^{*} \\
(0.22,0.89)\end{array}$ & $\begin{array}{c}0.45^{*} \\
(0.24,0.87)\end{array}$ \\
\hline Norway & $\begin{array}{c}1.03 \\
(0.58,1.84)\end{array}$ & $\begin{array}{c}0.89 \\
(0.56,1.42)\end{array}$ & $\begin{array}{c}1.88^{*} \\
(1.04,3.41) \\
\end{array}$ & $\begin{array}{c}1.07 \\
(0.67,1.70)\end{array}$ & $\begin{array}{c}3.29 * \\
(1.72,6.31)\end{array}$ & $\begin{array}{c}1.38 \\
(0.85,2.22)\end{array}$ & $\begin{array}{c}2.09 * \\
(1.04,4.21)\end{array}$ & $\begin{array}{c}1.97 * \\
(1.09,3.56) \\
\end{array}$ \\
\hline New Zealand & $\begin{array}{c}1.86^{*} \\
(1.11,3.13)\end{array}$ & $\begin{array}{c}1.79 * \\
(1.15,2.78)\end{array}$ & $\begin{array}{c}0.56^{*} \\
(0.33,0.93)\end{array}$ & $\begin{array}{c}0.69 \\
(0.44,1.07)\end{array}$ & $\begin{array}{c}1.20 \\
(0.68,2.11)\end{array}$ & $\begin{array}{c}1.53 \\
(0.96,2.46)\end{array}$ & $\begin{array}{c}1.49 \\
(0.76,2.94)\end{array}$ & $\begin{array}{c}1.31 \\
(0.71,2.45)\end{array}$ \\
\hline
\end{tabular}

Adjusted for number of individuals in household

Statistically significant results are indicated by a "*". Within these, results representing worse care for those in the high income group are shaded light orange, whereas those representing worse care for lower income groups are shaded light grey 


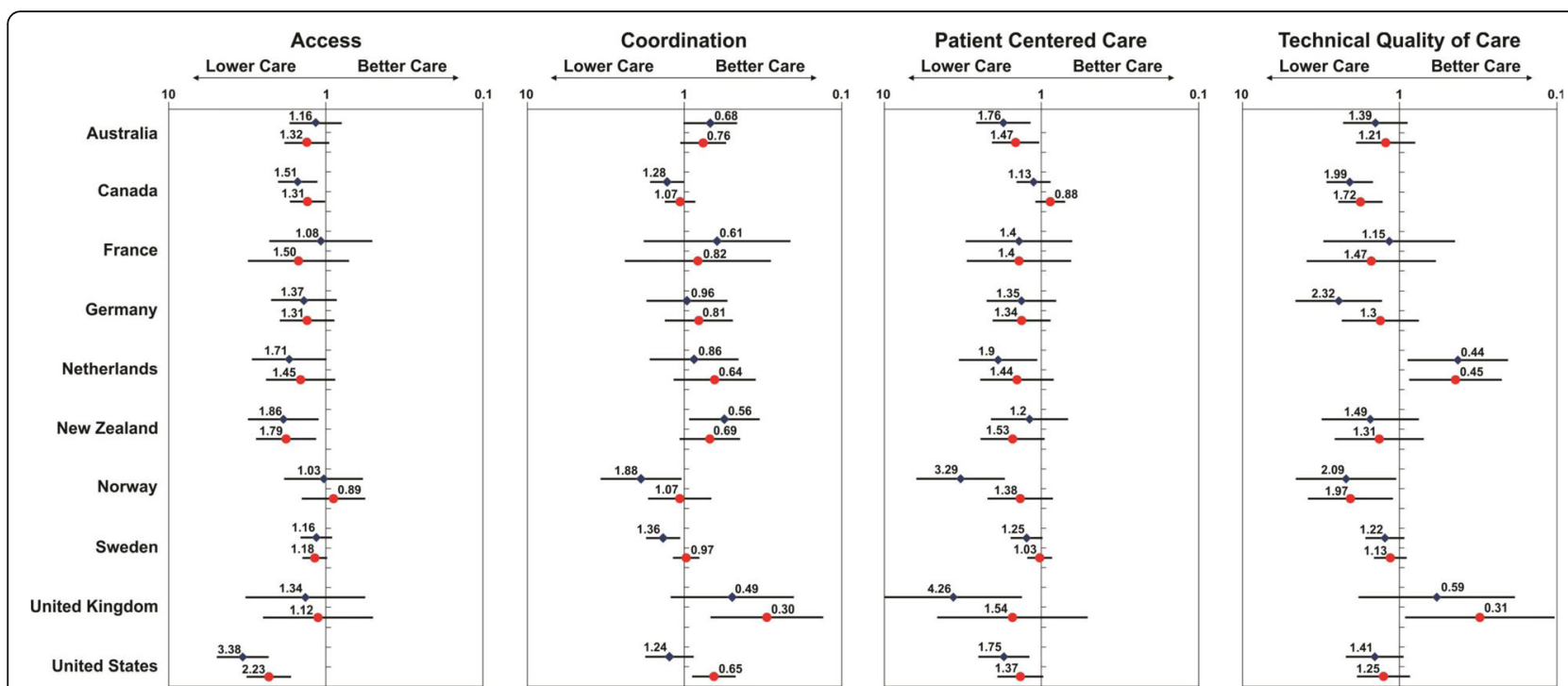

Fig. 1 Odds of reporting "poor" care for low and middle income categories relative to upper income category (reference to high income), adjusted for number of individuals in the household. The blue diamond and the red circle represent the odds ratio of individuals living in low income and middle income households, respectively, relative to those in high income households

\section{Discussion}

\section{Variation within and across countries}

This study is the first to examine the relationship between income inequality and experience of PC services cross-nationally. In our sample of "sicker adults" the main finding was that inequity in primary health care exists in virtually all countries in at least one dimension of care, although there were no within country trends that would point to deficiencies in that healthcare system that compromised equitable care delivery across the four dimensions. Within one country, the association between income status and quality of care sometimes favoured people with greater needs but usually followed the inverse care law in others [25]. The United Kingdom is an interesting example of the extent of variability in performance measure disparity within one country, where we observed the largest gaps in favour of (patient centered care, Odds ratio 4.26, 95\% CI [1.34-13.51), and against (technical quality of care, Odds ratio: $0.3195 \%$ CI [0.11-0.88]) individuals in the high income group within a single country. The results for two dimensions, access and patient centered care, point to the presence of a systemic issue affecting many countries.

\section{Dimensions}

\section{Access}

For virtually all countries, the direction of the association between income and access was in favour of high-income individuals. This reached statistical significance for three countries, where there was also evidence of a dose response association. The odds of reporting poor access increased from high to low income groups, strengthening the notion that the association may be causal [26]. The questions assessing access pertained to the availability and accommodation of PC services and the potential consequence of poor PC access (ER visits). None related to affordability [27]. At the time of this survey, strategies to improve access, such as PC performance benchmarking or PC financial compensation, had been adopted several years prior in Canada, Sweden, Australia, England and the Netherlands [28-30]. The results of this study suggest that these measures did not eliminate gaps in access across income strata in Canada and likely in the Netherland. These results are consistent with a recent systematic review in which no meaningful association was found between reimbursement structure and equitable access to PC across socio-economic groups [31].

\section{Patient centered care}

We also observed a dose-response pattern favouring high income individuals in patient centered care across most countries; with results achieving statistical significance in five How and why the individual's socio-economic situation may influence patient-centeredness is unclear. A possible explanation is that the usual encounter time allocation is insufficient to delivering quality Patient-centered Care for individuals with more complex needs [32], and individuals of lower socio-economic status are more likely to have complex needs. Patient centered care is also a complex concept to measure which studies have found to be influenced by patient expectations [33]. Some indicators used to measure patient centered care in this survey (e.g. Does your doctor spend enough time with you?) would likely be influenced by patient 
expectations. A recent study suggested that sociodemographic conditions contribute to reduced patient centered care mediated through to barriers in access to health information [34].

\section{Coordination}

There was no consistent trend in equitable delivery of coordinated or technical quality of care across countries. In some countries, individuals in the lower income groups reported better care in these dimensions than their high income counterparts. An analysis of the 2013 survey suggested that care coordination is positively related to encounter time and effective explanation of issues, physician knowledge of the patient's medical history, and patient engagement in care; [35] aspects of care frequently related to patient centeredness [36, 37]. However, we found no evidence of association between equity in these two measures within countries.

\section{Technical quality of care}

Three of the six technical quality of care indicators relate to process measures that are usually carried out by the family physician (blood pressure and foot examination, medication discussion) and the extent to which these are done may relate to adequate access to PC services. Three others are not solely tied to the PC service, but require the patient to access additional services (cholesterol, HbA1c and eye checks), which may pose additional access barriers.

\section{Countries}

In Norway, a country with universal public health care, despite having relatively fewer respondents (671) than in other countries, we observed statistically significant inequities across three of four dimensions (Table 3). However, Norway was the only country where there was no evidence of inequity in access to PC [23, 38]. These results are similar to a national survey of Norwegians that found respondents reported equal access to General Practitioners and inpatient hospital care but inequity in access to private specialists and outpatient hospital based care [38]. The authors suggest that income-based inequities at some point during the doctor/patient interaction might explain why they found income-based inequities in the utilization of private medical specialists by Norwegian adults [38]. In a separate study in Norway, the odds of reporting poor technical quality of care were approximately two times higher for lower-income patients versus the high-income patients in this sample which the authors felt could reflect a lack of reforms in Norway's health system that address a need for increased patient safety in PC [23]. Our data suggest that lower-income patients may be at a greater risk than high-income patients with regard to patient safety. This is especially important findings as our analyses revealed the largest differences in the self-reported health measure in Norway and the United States.

The Canada Health Act states that all Canadians, rich or poor, should have access to the same level of health care once insured through the publically funded health system [39]. Yet, Canadian findings showed significant evidence of income-based inequity in two dimensions; technical access and quality of care. Since Canada has a single-payer universal health system that eliminates access barriers related to service costs, the cause of this finding may lie in other barriers more indirectly related to the individual's financial situation. A recent phone audit study conducted in Ontario, Canada suggests that discrimination could play a role [40]. In that study, researchers contacted 375 PC Clinics in Toronto, and found that reception staff was more likely to offer an appointment to "patients" (actually the researchers) who they perceived as having a high socio-economic status versus those with a perceived low socio-economic status. Individuals in low income brackets also tend to have less flexibility in their work hours and may require higher scheduling accommodations. Geography and physician availability are most likely implicated as well. Rural areas are more likely to be inhabited by lower-income patients and while approximately $21 \%$ of Canadians live in rural areas, only $9.4 \%$ of family physicians provide service to rural areas [40]. Future studies should investigate the proportion of participants living in rural areas and assess the effects on ratings of access. Canadian findings also revealed inequities in the technical quality of care.

The US showed the highest gap for access to PC between the lower and higher-income group. This may be unsurprising, given the US health system's strong orientation toward specialized medicine, private insurance coverage and large population of uninsured citizens. The major discrepancy between the US and other participating countries on access is consistent with the concerns regarding affordability reported in a previous Commonwealth Fund survey [12, 41]. Since the time of the 2011 survey, the structure of the United States' health care system has undergone a significant shift as a result of the 2010 Affordable Care Act (ACA) (responsible for extending coverage to 22 million people nationally).

New Zealand results also showed significant inequity for access to PC. In other studies New Zealand has been shown to score well on several indicators of access to PC [12, 41]; though Emergency Department (ED) usage rates have been shown to be fairly high comparable to other nations (Canada and the US had the highest rates) [41]; A 2014-2015 report on ED use from the New Zealand Ministry of Health shows that ED usage rates were greater among patients who scored high on 
socio-economic deprivation [42]. New Zealand recently announced an expansion of their program to provide low-cost access to PC to the poorest in the country, an indication that this is a recognized problem. Further investigation is warranted to better understand these findings and the potential impact of the recent policy decisions. New Zealand and the United Kingdom had fewer individuals reporting problems in care coordination, and these countries showed pro-poor performance in these measures across income groups.

Sweden performed well on income-based equity with the exception of the low-income comparison on coordination. Recent health reforms in Sweden (i.e., the Choice reform in Stockholm County Council in 2008 and the Primary Health Care Choice Reform in 2010) could explain our results for Sweden on this dimension. These reforms were designed to increase access and patient choice by allowing PC providers to launch private for-profit practices, effectively terminating a health system of needs-based resource distribution. It has been suggested that these reforms primarily benefit the socially advantaged and that lower-income patients with complex needs experience difficulty obtaining integrated care [43].

France, Germany and the Netherlands similarly showed little evidence of income-based inequity on our dimensions of PC; however, a very high percentage of participants $(>70 \%)$ from these nations reported poor coordination of care, regardless of their income (Table 3). In fact, coordination was rated poorly by the majority of participants in nearly all countries [7].

\section{Limitations and future directions}

The data for this study were collected by the Commonwealth Fund and not originally intended for the purposes this study. There was a large variation in the individual countries' sample size and consequently statistical power to detect significant differences in the quality measure across income groups. The lack of statistical significance in the presence of an important effect size (e.g. Access in the Netherlands), and statistically significant findings that may not have a strong effect size (e.g. Coordination in Sweden) should be interpreted with caution. We sought to represent the burden of inequity across the individuals living in these countries. We did not seek to account for factors that can contribute or explain away these inequities.

Since there were few consistencies cross-nationally, it is plausible that macro-level health system policy or system configuration within each country could explain our results, including intra-country variation across dimensions.. Future work should examine the relationship between inequity in primary health care and health system factors, like physician remuneration and practice structure, health insurance design [44] and the implementation of specific PC reforms [43].

\section{Conclusion}

The findings presented in this paper broaden our understanding of the relationship between income and PC performance across the access, care coordination, patient centered care, and technical quality of care dimensions. It demonstrates that income related inequities in at least one dimension of care exist for nearly all participating OECD countries. While PC has been demonstrated to be an essential component of the health care system in promoting equitable access to health resources and reducing disparities in health across population strata, this study shows that income-based inequities are present within the walls of PC. It is essential that researchers and policy makers seek to uncover what makes a PC system more equitable to mitigate barriers to making quality $\mathrm{PC}$ accessible to all.

\section{Additional file}

Additional file 1: Appendix A. (DOCX $30 \mathrm{~kb})$

\section{Acknowledgements}

Thank you to Ilisha French, Justin Joschko and Mary Ivess, staff at the C.T. Lamont Primary Health Care Research Center for assistance with preparing the manuscript.

Funding

No new funding was received for this work.

\section{Availability of data and materials}

The datasets used and/or analysed during the current study are available from the corresponding author on reasonable request.

Authors' contributions

SD conceptualized the study, conducted the analyses and led the manuscript writing. EM, WH, TS, and SD planned the analyses, interpreted the data and contributed to the manuscript. All authors read and approved the final manuscript.

\section{Ethics approval and consent to participate}

The study was approved by the Bruyere Research Institute ethics board (study (M16-12-019), and and Ottawa Health Science Network research ethics board (20120125-01H). Informed consent was obtained from all participants.

\section{Consent for publication \\ N/A}

\section{Competing interests}

The authors declare that they have no competing interests.

\section{Publisher's Note}

Springer Nature remains neutral with regard to jurisdictional claims in published maps and institutional affiliations.

\section{Author details}

${ }^{1}$ Department of Family Medicine and Scientist at the Bruyère Research Institute and the Institute of Clinical Evaluative Sciences, University of Ottawa, Ottawa, Canada. ${ }^{2}$ Department of Family Medicine and Scientist at the Institut de Recherche de L'Hôpital Montfort and the Institute of Clinical Evaluative Sciences, University of Ottawa, Ottawa, Canada. ${ }^{3}$ Department of Family Medicine, The University of Ottawa, Ottawa, Canada. ${ }^{4}$ Institute of Health and Society, Newcastle University, Newcastle upon Tyne, UK. 
Received: 26 April 2018 Accepted: 13 November 2018

Published online: 12 December 2018

\section{References}

1. Macinko J, Starfield B. Annotated bibliography on equity in health, 19802001. Int J Equity Health. 2002;1:1.

2. Pickett KE, Wilkinson RG. Income inequality and health: a causal review. Soc Sci Med. 2015;128:316-26.

3. Wilkinson RG, Pickett KE. Income inequality and population health: a review and explanation of the evidence. Soc Sci Med. 2006;62:1768-84.

4. Shi L, Macinko J, Starfield B, Wulu J, Regan J, Politzer R. The relationship between primary care, income inequality, and mortality in US states, 19801995. J Am Board Fam Pract. 2003:16:412-22.

5. Van DE, Masseria C, Koolman X, OECD health equity research group. Inequalities in access to medical care by income in developed countries. CMAJ. 2006;174:177-83.

6. Institute of Medicine. Primary Care: America's Health in a New Era. Washington, DC: The National Academies Press; 1996.

7. Schoen C, Osborn R, Squires D, Doty M, Pierson R, Applebaum S. New 2011 survey of patients with complex care needs in eleven countries finds that care is often poorly coordinated. Health Aff (Millwood). 2011;30:2437-48.

8. Starfield B, Shi L, Macinko J. Contribution of primary care to health systems and health. Milbank Q. 2005;83:457-502.

9. Shi L, Starfield B, Politzer R, Regan J. Primary care, self-rated health, and reductions in social disparities in health. Health Serv Res. 2002;37:529-50.

10. Shi L, Starfield B, Kennedy B, Kawachi I. Income inequality, primary care, and health indicators. J Fam Pract. 1999;48:275-84.

11. World Health Organization. Declaration of Alma Ata. 1978. http://www.who. int/publications/almaata_declaration_en.pdf.

12. Schoen C, Osborn R, Doty M, Squire D, Peugh J, Applebaum SA. Survey of primary care physicians in 11 countries, 2009: perspectives on care, costs, and experiences. Health Affairs. 2009;28:w1171-83. http://content.health affairs.org/cgi/content/abstract/28/6/w1 171?ijkey=46Z9Be2ia7vm6\&keytype= ref\&siteid=healthaff.

13. Starfield B. Primary care: an increasingly important contributor to effectiveness, equity, and efficiency of health services. SESPAS report 2012. Gac Sanit. 2012:26:20-6.

14. Glazier RH, Agha MM, Moineddin R, Sibley LM. Universal health insurance and equity in primary care and specialist office visits: a population-based study. Ann Fam Med. 2009;7:396-405.

15. Beckman A, Anell A. Changes in health care utilisation following a reform involving choice and privatisation in Swedish primary care: a five-year follow-up of GP-visits. BMC Health Serv Res. 2013;13:452.

16. Hammouche S, Holland R, Steel N. Does quality of care for hypertension in primary care vary with postcode area deprivation? An observational study. BMC Health Serv Res. 2011;11:297.

17. Joshi C, Jayasinghe UW, Parker S, Del MC, Russell G, Lloyd J, et al. Does health literacy affect patients' receipt of preventative primary care? A multilevel analysis. BMC Fam Pract. 2014;15:171.

18. Shah BR, Cauch-Dudek K, Anand SS, Austin PC, Manuel DG, Hux JE. Absence of disparities in the quality of primary diabetes care for south Asians and Chinese in an urban Canadian setting. Diabetes Care. 2012;35:794-6.

19. Borkhoff CM, Saskin R, Rabeneck L, Baxter NN, Liu Y, Tinmouth J, et al. Disparities in receipt of screening tests for cancer, diabetes and high cholesterol in Ontario, Canada: a population-based study using area-based methods. Can J Public Health. 2013;104:e284-90

20. Lofters A, Mark A, Taljaard J, Green M, Glazier R, Dahrouge D. Cance screening inequities in a time of primary care reform: a population-based longitudinal study in Ontario, Canada. BMC Fam Pract. 2018; in press.

21. Ward PR. The relevance of equity in health care for primary care: creating and sustaining a 'fair go, for a fair innings. Qual Prim Care. 2009;17:49-54.

22. Haggerty J, Burge F, Levesque JF, Gass D, Pineault R, Beaulieu MD, et al. Operational definitions of attributes of primary health care: consensus among Canadian experts. Ann Fam Med. 2007;5:336-44.

23. OECD: OECD reviews of health care quality: Norway 2014. 2014.

24. OECD. Terms of reference - OECD project on the distribution of household incomes. 2016. https://www.oecd.org/statistics/data-collection/ Income\%20distribution_guidelines.pdf

25. Marmot M. An inverse care law for our time. BMJ. 2018;362:k3216.

26. Agency for Healthcare Research and Quality RMD, Pickett KE, Wilkinson RG. Population Health: Behavioral and Social Science Insights:Income Inequality and Health: A Causal Review. 2018. https://www.ahrq.gov/professionals/ education/curriculum-tools/population-health/pickett.html.

27. Levesque JF, Harris MF, Russell G. Patient-centred access to health care: conceptualising access at the interface of health systems and populations. Int J Equity Health. 2013;12:18.

28. Hutchison B, LEVESQUE JEAN, Strumpf E, Coyle N. Primary health care in Canada: systems in motion. Milbank Q. 2011;89:256-88.

29. Willcox S, Lewis G, Burgers J. Strengthening primary care: recent reforms and achievements in Australia, England, and the Netherlands. Issue Brief (Commonw Fund). 2011;27:1-19.

30. Anell A. Choice and privatisation in Swedish primary care. Health Econ Policy Law. 2011;6:549-69.

31. Tao W, Agerholm J, Burstrom B. The impact of reimbursement systems on equity in access and quality of primary care: a systematic literature review. [review]. BMC Health Serv Res. 2016:16:542.

32. Dunn N. Practical issues around putting the patient at the Centre of care. J R Soc Med. 2003;96:325-7.

33. Rao JK, Weinberger M, Kroenke K. Visit-specific expectations and patientcentered outcomes: a literature review. [review] [39 refs]. Arch Fam Med. 2000;9:1148-55.

34. Clarke MA, Moore JL, Steege LM, Koopman RJ, Belden JL, Canfield SM, et al. Health information needs, sources, and barriers of primary care patients to achieve patient-centered care: a literature review. [review]. Health Inform J. 2016;22:992-1016.

35. Penm J, MacKinnon NJ, Strakowski SM, Ying J, Doty MM. Minding the gap: factors associated with primary care coordination of adults in 11 countries. Ann Fam Med. 2017;15:113-9.

36. Little P, Everitt H, Williamson I, Warner G, Moore M, Gould C, et al. Preferences of patients for patient centred approach to consultation in primary care: observational study. BMJ. 2001;322:468-72.

37. Stewart M. Towards a global definition of patient centred care. BMJ. 2001; 322:444-5.

38. Vikum E, Krokstad S, Westin S. Socioeconomic inequalities in health care utilisation in Norway: the population-based HUNT3 survey. Int J Equity Health. 2012:11:48.

39. Health Canada. Canada health act: Annual Report 2010-2011. 2011. 5-14-2017.

40. Olah ME, Gaisano G, Hwang SW. The effect of socioeconomic status on access to primary care: an audit study. CMAJ. 2013;185:E263-9.

41. Schoen CORDMMBMPJ\&MN. Toward higher performance health systems: adults' health care experiences in seven countries. Health Aff (Millwood). 2007;26:717-34

42. Ministry of Health. Emergency Department Use 2014/15. Wellington: Ministry of Health; 2016.

43. Burstrom B, Burstrom K, Nilsson G, Tomson G, Whitehead M, Winblad U. Equity aspects of the primary health care choice reform in Sweden - a scoping review. Int J Equity Health. 2017;16:29.

44. Schoen C, Osborn R, Squires D, Doty MM, Pierson R, Applebaum S. How health insurance design affects access to care and costs, by income, in eleven countries. Health Aff (Millwood ). 2010;29:2323-34.

Ready to submit your research? Choose BMC and benefit from:

- fast, convenient online submission

- thorough peer review by experienced researchers in your field

- rapid publication on acceptance

- support for research data, including large and complex data types

- gold Open Access which fosters wider collaboration and increased citations

- maximum visibility for your research: over $100 \mathrm{M}$ website views per year

At $\mathrm{BMC}$, research is always in progress.

Learn more biomedcentral.com/submissions 